\title{
Research on the Evaluation Index System of Power Market Operation under the Plan-and-Market Dual System
}

\author{
Ming Zeng ${ }^{1}$, Shiyu Meng ${ }^{1, \text { a }}$, Pengcheng Zhou ${ }^{1}$, Yan Yang ${ }^{1}$, Lei Wang ${ }^{2,3}$, \\ Peiyu $\mathrm{Xi}^{2,3}$, Chenjun Sun ${ }^{4}$
}

${ }^{1}$ School of Economics and Management, North China Electric Power University, Beijing 102206, China;

${ }^{2}$ NARI Group Corporation, Nanjing 210003 China;

${ }^{3}$ Beijing Kedong Electric Power Control System Co., Ltd. Beijing 100194, China;

${ }^{4}$ State Grid Hebei Electric Power Company, Hebei 050000, China.

a1173416446@qq.com

Keywords: Dual system, Electricity market, Market transaction.

\begin{abstract}
With the increasing proportion of the electricity in the market, more and more new market participants are involved in the market competition and the new trading variety also comes into being, which has put forward new demand for the statistical analysis of power transaction operation. Considering the influence of electric reform policy on market transaction under the dual system of plan and market, the paper builds the evaluation index system of power market operation based on the existing index system of the current evaluation of power transaction operation at home and abroad.
\end{abstract}

\section{Introduction}

The statistical analysis under the planned system is mainly carried out around the transaction plan. The main indexes of the analysis are the implementation of the planned electricity and the data analysis of the three public schedule, which is not enough to support the bidding situation and market status analysis after the reform of the power system. Therefore, it is of great significance to establish an evaluation index system for power market operation under the dual system of planning and market.

Considering the new situation, the planning system and the market system will exist for a long time. The evaluation system of the power market operation, which focuses on the power production plan and execution, is unable to adapt. It is necessary to gradually strengthen and expand the key indicators and analysis dimensions that can reflect the operation of the power market. The current statistical analysis focuses on the transaction, contract, plan and settlement, and provides basic data statistics and analysis. Its supporting capacity is limited. The existing statistical analysis system and index system need to be properly enriched and perfected to meet the needs of the existing statistical analysis business and promote the lean power grid enterprises. The improvement of management level reflects the development of electricity market objectively and comprehensively.

From the aspects of business types, market characteristics and transaction management, the paper further improves the evaluation index base of power market operation situation according to the transaction content and business needs of the current market transition period and constructs an evaluation index system for power market operation to adapt to the dual system.

\section{Analysis of Dual Institutional Features}

Under the dual system of planning and market, the market subject, market trading variety and trading mechanism are diversified and complicated. Under dual system, the characteristics of the plan coexist with the market characteristics, which are mainly embodied in the cooperative characteristics of the plan and the market.

Synergy mainly reflects the evolution process of electricity market under different systems. In fact, under the dual system, the goal of the power market operation is to achieve effective competition, that 
is, the goal is to achieve the effective coordination between the scale plan and the competitive vitality. At the same time, it is necessary to form a competitive pattern conducive to long-term equilibrium so as to achieve effective allocation of resources. The realization of this goal is the evolution of the electricity market from disorder to order.

Under the current dual institutional environment, the power industry has changed from the traditional vertical integration model to today's power-selling side and competition in transmission and distribution costs. The series of reforms has caused tremendous changes in the power industry. Under the planned system, the power industry is a vertically integrated vertical monopoly production structure. The power industry lacks internal development momentum, lacks market vitality, and has low market operating efficiency.

Under the dual system of plans and markets, the reform of the power sales side has been further advanced. The reform of transmission and distribution prices has been carried out in various provinces. Increasing emphasis has been placed on the field of incremental distribution networks. The traditional monopoly structure has been broken down and multiple market players have emerged. However, as the current reform of the electricity market is in a stage of advancement, complete reforms have not been achieved, which has led to factors, such as environmental conditions in the traditional electricity market still constraining the operation of the electricity market. The operation of the power market is affected by many factors, mainly manifested in the coordination and unification of the current scale plan and market competition, that is, the power market operation under the dual system is cooperative.

\section{The Construction of Evaluation Index System}

The most fundamental role of electricity market operation is to ensure the safety of electricity production and transportation. On this basis, the role is mainly reflected in ensuring the fairness of electricity market transactions and the optimal allocation of resources. In the evaluation of the operation of the power market, it is necessary to establish a set of evaluation index systems covering all aspects of market operations in order to ensure that the competitive power market can meet the interests of market members. Therefore, the paper mainly establishes the basic framework of the evaluation index system for electricity market operation from the following three aspects, including market operation, market efficiency and market efficiency.

Market operation plays a very important role in the electricity market. Under the new round of power system reform environment, the electricity market has been affected and the major changes have taken place in the power market trading activities. Under such circumstances, assessing the operation of the electricity market and drawing on the results of assessments will be conducive to the timely adjustment of trading content such as trading power in a new environment, which will have very important practical significance for regulating the electricity market. With the further advancement of the new round of power system reforms, the complexity of ensuring the safe and stable operation of the power grid has increased, which has brought greater challenges to the safe and stable operation of the power grid. At the same time, the interest coordination among market players is complicated, and the market-oriented trading mechanism needs to be improved, which imposes higher requirements on power market control measures and transaction processing capabilities.

Market efficiency refers to the ability of the market to optimize the allocation of resources under the influence of various factors such as the behavior of market members and supply and demand conditions under the regulation of the electricity industry policy, which reflects the allocation of resources to the electricity market. The level of market efficiency is directly related to the function of the power market mechanism, especially the effective allocation of economic resources. It is the great significance to conduct a comprehensive and objective evaluation of the operation of the power market. With the gradual liberalization of the power-selling-side market and the gradual advancement of the transmission and distribution pricing reforms, the power industry has changed from the traditional integration model to power-supply-side and transmission-distribution links. The power industry has undergone tremendous changes. The old structure has undergone tremendous 
changes. After being broken, all members of the power market have re-understood their responsibilities and actively adjusted their strategies to achieve synergies with other members and improve their own benefits. Therefore, the section sets the evaluation index of market efficiency and mainly evaluates the effects of the market behaviors of the market players by considering both the coordination and competition.

The market efficiency refers to the actual state that the power market achieves in terms of economic benefits and market externalities through certain market behavior under a certain market structure. Market operation determines market efficiency and market operation determines market efficiency. The evaluation of market efficiency is multi-faceted and multi-level. The ultimate goal is to assess whether the system can effectively operate and optimize the allocation of resources through market efficiency evaluation. Therefore, under the competitive and open environment, the paper uses market methods to evaluate whether the optimal operation of the electricity market and the optimal allocation of resources are under the combined effect of appropriate regulation and free competition. The evaluation process of market efficiency is the process of evaluating the effectiveness of resource allocation. When the power market resource allocation reaches the Pareto optimal state, the social welfare as the sum of consumer surplus and producer surplus is the largest and the economic operation efficiency is optimal.

\section{Study on Electric Power Market Operation Evaluation System}

In the paper, according to the characteristics of the operation of the power market under the dual system of plan and market, the general idea of establishing the index system is to summarize the index system proposed by the scholars from different angles, put forward new typical indexes and select the main indexes reflecting the effect of the market operation.

Table 1. Evaluation index system of power market operation under dual system

\begin{tabular}{ccc}
\hline $\begin{array}{c}\text { First-level } \\
\text { indicators }\end{array}$ & Second-level indicators & Third-level indicators \\
\hline $\begin{array}{c}\text { Market } \\
\text { operation }\end{array}$ & Trading power & $\begin{array}{c}\text { The trading power growth rate } \\
\text { The electricity directly traded power ratio }\end{array}$ \\
$\begin{array}{c}\text { Market } \\
\text { efficiency }\end{array}$ & $\begin{array}{c}\text { The effectiveness of } \\
\text { price signals }\end{array}$ & $\begin{array}{c}\text { The ratio of growth rate of transaction electricity price to the } \\
\text { growth rate of consumer price index }\end{array}$ \\
$\begin{array}{c}\text { Market } \\
\text { benefit }\end{array}$ & $\begin{array}{c}\text { The use of clean } \\
\text { energy }\end{array}$ & $\begin{array}{c}\text { The ratio of the growth rate of transaction electricity price to } \\
\text { the growth rate of thermal coal price } \\
\text { The new energy consumption growth rate } \\
\text { The proportion of clean energy installed capacity }\end{array}$ \\
\hline
\end{tabular}

\subsection{Market Operation.}

Market operation mainly refers to trading power. The transaction power includes the trading power growth rate and the electricity directly traded power ratio.

The trading power growth rate refers to the ratio of the difference between current market trading power and the previous market trading power and the previous period market trading power.

$$
Q_{s c}=\frac{Q_{i}^{s c}-Q_{i-1}^{s c}}{Q_{i-1}^{s c}}
$$

In the formula, $Q_{i}^{s t}$ is the current market trading power and $Q_{i-1}^{s t}$ is the previous market trading power. The ratio of the difference between current market trading power and the previous period's market trading power and the previous period's market trading power reflects the year-on-year growth of market trading power, which reflects the market trading situation in the market operation.

The electricity directly traded power ratio refers to the ratio of direct transaction electricity to total market electricity.

$$
R_{u r}=\frac{Q_{w r}}{Q_{t}}
$$

In the formula, Qu is the direct trading power for large users and Qtr. is the total trading power in the market. Among them, the total trading power of the market reflects the active level of power 
trading and the change trend of power demand and supply can be known through its changing trend. The total amount of electricity traded in the market mainly includes the direct electricity trading power, trading power generation rights and electricity transmission trade. The proportion of direct electricity traded electricity in the market to total electricity traded reflects the degree of activity in the market for direct trading between electricity users and power generation companies.

\subsection{Market Efficiency.}

Market efficiency is mainly reflected in the validity of price signals, including the ratio of growth rate of transaction electricity price to the growth rate of consumer price index and the ratio of the growth rate of transaction electricity price to the growth rate of thermal coal price.

The ratio of growth rate of transaction electricity price to the growth rate of consumer price index (CPI) can be defined as:

$$
\gamma_{P}=\frac{\left(P_{i}-P_{i-1}\right) \cdot C P I_{i-1}}{P_{i-1} \cdot\left(C P I_{i}-C P I_{i-1}\right)}
$$

In the formula, $P_{i}$ is the transaction power price for this year, $P_{i-1}$ is the transaction power price for the previous year, $C P I_{i}$ is the consumer price index for the current year and $C P I_{i-1}$ is the consumer price index for the previous year. The ratio of the rate of change of transaction electricity price to the rate of change of CPI is mainly used to analyze the benefits generated by electricity market operations in terms of electricity prices, and it can effectively reflect the fluctuations and changes in market electricity prices and provide a reasonable assessment of electricity price levels.

The ratio of the growth rate of transaction electricity price to the growth rate of thermal coal price can be defined as:

$$
P M=\frac{\Delta P_{\mathrm{ur}}}{\Delta P_{M}}
$$

In the formula, $\Delta P_{u r}$ is the rate of change of transaction electricity price, and $\Delta P_{M}$ is the rate of change of electric coal price.

\subsection{Market Benefit.}

The market efficiency is mainly reflected in the use of clean energy, including the new energy consumption growth rate and the proportion of clean energy installed capacity.

The new energy consumption growth rate is the year-on-year growth of new energy consumption.

$$
\alpha_{n c x}=\frac{Q_{i}^{r e x}-Q_{i-1}^{r e x}}{Q_{i-1}^{r x x}} * 100 \%
$$

In the formula, $Q_{i}^{\text {rex }}$ is the new energy unit generating capacity consumed in the current period, and $Q_{i-1}^{r e x}$ is the new energy unit generating capacity consumed in the previous period.

The proportion of clean energy installed capacity refers to the proportion of clean energy installed capacity in total installed capacity.

$$
R_{R E}=\frac{P_{R E}}{P_{S}}
$$

In the formula, PQJ is the installed capacity of clean energy and PS is the total installed capacity.

\section{Conclusion}

With the gradual liberalization of the power-selling side of the market, based on the clear and step-by-step implementation of reforms, the market plays a decisive role in resource allocation. Under the background of the dual system of planning and market, the paper mainly constructs the evaluation index system of electricity market operation under the dual system background based on the index system of statistical analysis of power trading under the planned system. 


\section{Acknowledgments}

The paper is supported by the technical project of State Grid Corporation of China (Research on Management Mode, Analysis Method and Statistical Analysis of Power Purchasing under Plan-and-market dual System).

\section{References}

[1]. Abiola I. Adebayo, Payam Amani- Dehkordi, Hamidreza Zareipour, et al. Impacts of transmission tariff on price arbitrage operation of energy storage system in Alberta electricity market. Utilities Policy. 2017.

[2]. Alexander Zip. The marketability of variable renewable energy in liberalized electricity markets - An empirical analysis. Renewable Energy. 2017.

[3]. Chen-Hao Tsai, Yi-Lin Tsai. Competitive retail electricity market under continuous price regulation. Energy Policy. 2018.

[4]. Goksel Asan, Kamil Tasaltin. Market efficiency assessment under dual pricing rule for the Turkish wholesale electricity market. Energy Policy. 2017.

[5]. Shahab Bahrami, M. Hadi Amini. A decentralized trading algorithm for an electricity market with generation uncertainty. Applied Energy. 2018.

[6]. Fehmi Tanrisever, Kursad Derinkuyu and Geert Jongen. Organization and functioning of liberalized electricity markets: An overview of the Dutch market. Renewable and Sustainable Energy Reviews. 2015. 